\title{
HISTÓRIA, MULHERES E EXISTENCIALISMO: NARRATIVAS FEMINISTAS NA IMPRENSA BRASILEIRA NO SÉCULO XX.
}

\section{HISTORY, WOMEN AND EXISTENCIALISM: FEMINIST NARRATIVES IN THE BRAZILIAN PRESS IN THE TWENTIETH CENTURY.}

\section{Danielle Silva Moreira dos Santos ${ }^{1}$}

Resumo: Considerando que a narrativa, seja ela histórica ou ficcional, desempenha importante papel na organização e constituição de sentido para a vida humana, o presente artigo, propõe-se a refletir brevemente, a partir da perspectiva existencialista, como mulheres escritoras que se reuniram para produzir periódicos direcionados ao público feminino brasileiro no século XX, especialmente em Goiás, elaboraram um sentido para a existência feminina, através da criação de identidade(s) feminina(s), representadas em suas produções textuais.

Palavras Chaves: Identidade, feminismo, imprensa.

Abstract: Considering that the narrative, historical or fictional, plays an important role in the organization and constitution of meaning for human life, this article proposes to reflect briefly, from the existentialist perspective, as women writers who gathered to produce periodicals aimed at the Brazilian female public in the 20th century, especially in Goiás, developed a meaning for the feminine existence, through the creation of feminine identities, represented in their textual productions.

Key Words: Identity, feminism, press.

\section{A HISTÓRIA, A NARRATIVA E A VIDA.}

A nossa existência é finita e se desenvolve no tempo e no espaço. Uma das maneiras encontradas pelos seres humanos para se organizarem e se orientarem nesse percurso finito do tempo foi construindo narrativas, ficcionais ou não, como apontaram pesquisadores como Paul Ricouer ${ }^{1}$. Segundo Ortega y Gasset (1982) a experiência é definida como um conhecimento acumulado do que somos, conservado pela nossa memória, portanto, nossas experiências dependem do nosso passado, e é construindo narrativas sobre esse passado, que cada indivíduo encontra meios para organizar suas experiências, refletindo acerca das mesmas.

\footnotetext{
${ }^{1}$ Paul Ricouer (1994) levanta a hipótese de que existe uma relação entre a atividade de narrar e o caráter temporal da existência humana, para ele o tempo toma uma perspectiva ${ }^{1}$ Mestranda GEPEG/UFG dan.historia.ufg@gmail.com
}

Numa definição mais poética, Peter Gay, ao analisar a experiência burguesa no século XIX, defende que a experiência seja resulte do encontro da mente com o mundo:

\begin{abstract}
Muitos mais do que proporcionar um exercício estereotipado do raciocínio e da ação, a experiência participa da criação dos objetos do interesse e da paixão; da forma aos anseios ainda incipientes e levanta barreiras contra ansiedade ameaçadoras (1988, p.19).
\end{abstract}

Dessa forma, aquilo que nós somos depende intimamente do que nós experimentamos, dos traumas, realizações e superações que vivenciamos ao longo da vida. A experiência é algo individual, contudo, existe uma intersecção entre as experiências particulares e as coletivas; "a eminentemente humana quando é organizado, articulado através da narrativa. 
experiência da vida não se compõe apenas das experiências que cada um tem pessoalmente do seu passado. Ela também é integrada pelo passado dos antepassados que a sociedade na qual vivemos nos transmite"(ORTEGA Y GASSET, 1982, p.46).

Nesse sentido, a História é a parte das ciências humanas que investiga o passado dos antepassados da nossa sociedade, preocupando-se com questões que compuseram o quadro da vida de homens e mulheres em um determinado momento pretérito. Classificada como parte das ciências humanas e dotada de métodos e princípios próprios, a história e as narrativas que ela produz, adquirem caráter próximo às narrativas das ciências designadas exatas ${ }^{2}$, na medida em também resulta em "verdades" que organizam o mundo da vida, através da linguagem e representam uma tentativa humana de conferir sentido para tudo com o que nos deparamos em nossa caminhada existencial, buscando resposta para seus medos, dúvidas, ambições e inquietações. Nessa mesma direção, acrescentamos também, as narrativas literárias que também cumprem o papel de orientar a organizar a vida humana dando vazão a essas angustias e inquietações, operando como um tipo de conhecimento artístico e intelectual.

Segundo Scott (1999) a história não pode separar a linguagem e a experiência, pois a linguagem é o local onde a história acontece, onde a história é encenada, e a experiência é definida por Scott como a história do sujeito ${ }^{3}$.

\footnotetext{
${ }^{2}$ Segundo Ortega y Gasset a histórica pode ser considera tão racional e rigorosa quanto às ciências exatas, além disso, e em ambas as razões, tanto a histórica quanto a físico-matemática, existe um caráter narrativo. "Frente à razão pura físico-matemática existe, portanto, uma razão narrativa. Para compreender algo humano, pessoal ou coletivo, é necessário contar uma história''(1982, p.48).
}

A noção de uma história exemplar, magistra vitae, originada em tempos medievais, orientado por uma perspectiva cristã do tempo onde o futuro já estava predeterminado pelo juízo final, caie em desuso a partir da modernidade. Segundo Ivan Domingues (1996), a modernidade foi o momento em que a consciência humana da sua inserção no tempo se intensificou, a humanidade deixou de caminhar para o juízo final, o futuro se tornou indefinido, imprevisível e a História passou a ser analisada de maneira mais otimista, entendida como o caminho em direção ao progresso e ao aprimoramento humano. A história deixou de ser a o estudo do passado, para ser a ciência do presente, haja vista, que ficou evidente, para os historiadores, que as inquietações que fazem os seres humanos buscarem respostas passadas surgem no presente, o passado assim só se revela quando solicitado por alguém presente (RUSEN, 2008).

Além da relação entre passado, presente, futuro, outra questão que recaiu sobre a história, a partir das mudanças na concepção temporal, foi a sua utilidade para a vida prática. A vida é um processo não apenas biológico, mas também social (RUSEN, 2008), e essa constatação instigou vários intelectuais a se aterem a essa peculiar relação entre a História e a vida. A história passou a ser alvo de questionamentos acerca da sua responsabilidade na construção de sentido na vida dos sujeitos.

\footnotetext{
3 A linguagem e a cultura são os pontos de encontro entre a história e a literatura, mas apesar desses dois conhecimentos estarem constantemente em diálogo, ambos os eixos narrativos tem pretensões distintas e resguardam uma distância epistemológica, que não é nosso o objetivo aprofundar nesse artigo.
} 
O ser humano é uma "infinidade plástica", (ORTEGA Y GASSET, 1982, p.44), não tem uma natureza determinante e sim história. Portanto, podemos considerar que uma das maneiras pela qual a História interfere na vida prática é na medida em que ela inventa, cria, engendra identidades ${ }^{4}$ que ajudam a moldar nossa infinidade plástica. Segundo a historiadora Joan Scott (1999), o conceito de identidade é estabelecido através de complexos processos discursivos e está intimamente envolvido com a ideia de experiência. Para forjar o seu en cada indivíduo recorre, também, ao passado, tanto individual como coletivo, para encontrar meios de elaborar uma identidade que possa designar de sua.

É precisamente por que as identidades são construídas dentro e não fora do discurso que nós precisamos compreendê-las como produzidas em locais históricos e institucionais específicos por estratégias e iniciativas específicas. Além disso, elas emergem no interior do jogo de modalidades específicas de poder e são, assim, mais produtos da marcação da diferença do que signo de uma unidade idêntica (HALL, 2000, p.109).

Essas identidades amparam os indivíduos e suas ações futuras, promove conforto emocional, estabilidade, oferecem senso de pertencimento a um grupo, auxiliando assim o sujeito a se localizar e a se compreender no espaço e no tempo. Nesse caso, historicamente, homens e mulheres, vivenciando experiências diferentes em decorrência de seu gênero, elaboram

\footnotetext{
4 Segundo Stuart Hall (2000) o conceito de identidade apesar de não ser mais adequado, para o contexto de globalização, ainda não foi superado e, portanto, não pode ser abandonado totalmente. Desde Foucault, o que houve
}

contextualmente, identidades, quase sempre diferentes e opostas em relação ao outro.

Ao longo do século XX a identidades de gênero se transformaram. Perante as mudanças políticas e sociais surgiram novas possibilidades de identidades. Scott explica que o surgimento de novas identidades não ocorre de forma inevitável ou acidental, uma identidade "não é algo que sempre esteve lá esperando para ser representado, muito menos algo que sempre irá existir na forma que lhe foi dada em um movimento político específico ou em um momento histórico particular" (SCOTT, 1999, p.41).

Nosso foco reside, portanto, nessa maleabilidade das identidades e sua relação com a existência feminina, através de narrativas literárias e filosóficas. Analisando brevemente as identidades femininas que foram surgindo no início do século $\mathrm{XX}$ no seio do movimento feminista.

Por muito tempo, como demonstra a atual historiografia, e em certa medida até hoje, os discursos jurídicos, educacional, religiosos e científicos que se perpetuaram através das gerações, acabaram por limitar e influenciar a vida de homens e mulheres. A identidade masculina relacionada ao mundo público e a política e a identidade feminina ligada ao mundo privado e a família, inicialmente, é um exemplo de como as relações de poder estabeleceram historicamente discursos que moldaram identidades de gênero assimétricas e hierárquicas, mas consideramos o

foi uma reflexão sobre conceito de identidade a partir das práticas discursivas. Sendo assim, a identidade não pode ser pensada como unidade coesa, o mais adequado é partir da perspectiva da identificação que enfatiza a constituição constante e a subjetividade dos indivíduos. 
século XX como um momento importante para se pensar essas identidades, pois foi justamente quando esse conceito foi amplamente discutido.

\section{MULHERES NA HISTÓRIA E NA IMPRENSA LITERÁRIA}

Ao tentar extrair do passado um sentido para as relações entre homens e mulheres do presente, os historiadores do século XX constataram que por muito tempo foi negado às mulheres o "direito a História". O que Michele Perrot (2015) chamou de silenciamento ou invisibilidade feminina, foi o processo pelo qual a história política e econômica, com seus métodos e objetivos, inviabilizou, por muito tempo, a presença feminina. A questão feminina conduziu várias pesquisadoras e pesquisadores aos discursos do passado contidos nas fontes relacionadas às "atividades "masculinas", como a guerra e a política. Nesses documentos as mulheres, evidentemente pouco apareciam. Foi com o recente advento da História cultural ${ }^{5}$, com o alargamento das fontes e dos temas, que as mulheres começaram a marcar presença, através de estudos sobre o cotidiano, a família, o privado e doméstico.

Em seus estudos Foucault atesta que através do binômio saber-poder as instituições religiosas, educacionais, médicas e jurídicas, marcadas pela presença majoritariamente masculina, construíram o sujeito feminino

\footnotetext{
${ }^{5}$ Segundo Perrot (2015) a mulher emerge como objeto histórico durante a segunda metade do século XX. A tradição das escolas dos Annales que surge na primeira metade desse mesmo século, também colaborou na medida em que rompeu com a visão da eminente política da história, mas ainda assim, não tomavam a diferença entre os sexos como ponto de partida para as análises. Foi apenas
}

(RAGO, 2015, p.266). Inúmeras narrativas, livros e tratados produzidos, colaboraram para que as mulheres tivessem sua inteligência e suas potencialidades desmerecidas, fossem taxadas de débeis, incapazes, pecadoras e degeneradas.

Todas essas prerrogativas afirmavam historicamente o espaço doméstico como o ambiente ao qual a mulher deveria permanecer e dedicar sua existência com alegria e humildade. Espaço ideal onde a identidade feminina foi forjada ao alcance do olhar vigilante e punitivo dos homens de outras mulheres. Nessa incessante cruzada, que visava proteger a mulher de si mesma, evidentemente, nem todas se "salvavam" e a punição para os desvios de conduta resultavam em coerções ainda mais severas.

O confinamento, firmado na justificativa de proteção ao corpo feminino, resultou numa interdição, numa segregação não apenas física, mas também intelectual, já que a presença da mulher nas escolas não era aceita. A proibição ao acesso à educação, de maneira análoga, foi um caminho escolhido para supostamente proteger e preservar a mulher, tentando garantir assim a conservação integral da sua reputação física e moral.

A crença na inferioridade intelectual feminina e a defesa da manutenção desta ignorância, fez com que por séculos, o acesso ao conhecimento fosse vetado às mulheres. No Brasil a educação feminina se tornou uma das primeiras e mais importantes bandeiras do feminismo antes

por volta de 1970 com a renovação de sistemas de pensamento como o marxismo, quando a história aliou-se a antropologia e passou a valorizar a subjetividade, que surge a história das mulheres. O contexto social que contava com a maior presença feminina nas universidades e com o movimento feminista também foi elemento decisivo. 
mesmo do século XX. Mulheres como a professora nordestina Nísia Floresta, (1810-1885) concentraram seus esforços na defensa da educação feminina, alegando que a educação de toda sociedade, inclusive das mulheres, seria benéfico para o progresso do país.

Paulatinamente, professores particulares e colégios femininos colocaram as mulheres em contato com assuntos considerados adequados a elas ${ }^{6}$. Ler e escrever eram o básico, e o essencial não ultrapassava o ensino religioso, bordado, costura, culinária, música e pintura. Iniciando uma nova etapa de desigualdades entre homens e mulheres, através dos currículos distintos e ambientes separados ${ }^{7}$.

As mulheres eram instruídas a fazer um bom dos conhecimentos adquiridos, empregandoos no bom funcionamento do lar e na preservação da harmonia familiar. A leitura ideal abarcava manuais de comportamento, textos bíblicos. A escrita era comumente usada para estabelecer comunicação com familiares e permitia a manutenção de diários íntimos. Contudo, independente da forma com que as mulheres deveriam aplicar ou usufruir da escrita e da leitura, essas práticas se tornaram oportunidades para que elas se reinventassem. Todas essas práticas,

\footnotetext{
${ }^{6}$ Segundo Ivan A. Manoel, (1996) no Brasil, a partir do século XIX a educação feminina passou a ser amais profundamente discutida. Em meio a posições favoráveis e contrárias, permanecia a sensação de que as mulheres estavam sendo despertadas para novas possibilidades de atuação, inclusive no mundo público, então educar as moça tornou-se uma enorme preocupação para elite, que juntamente com a Igreja católica reivindicam o direito a organizar conduzir a educação das moças, na tentativa de evitar que essas incorporassem os novos comportamentos através de ideias feministas e liberais, comportamentos considerados nocivos e inadequados. Nesse contexto, houve a expansão das escolas católicas separadas de acordo com o sexo.
}

principalmente as escritas, funcionavam como uma válvula de escapa e proporcionaram reflexão, pois na medida em que essas mulheres narravam suas vidas essas mulheres e se comunicavam com conhecidos, elas também tinham a oportunidade de avaliar suas condutas e sentimentos.

\section{As punições para as mulheres que} ultrapassavam os limites impostos socialmente, não impediu que várias delas, principalmente aquelas pertencentes aos grupos de elite, se lançassem no mundo público inicialmente através da escrita. Pouco a pouco, as letras femininas, limitadas ao recôndito privado, ganharam o mundo, através dos meios de comunicação como jornais, revistas e livros.

Segundo Scott (1999) os sujeitos são constituídos através da experiência, sendo assim a experiência feminina com as letras, esse acesso feminino a escrita, ainda que tardio em relação aos homens, foi um importante instrumento para que a mulher se reinventasse, ao mesmo tempo, significou também uma atitude fundamental para que hoje, ao ter acesso a essas produções, os historiadores pudessem chegar a conceitos como o de gênero $^{8}$, que contempla as mulheres e suas experiências.

\footnotetext{
${ }^{7}$ Saber mais consultar MUNIZ, Diva do Couto G. MUNIZ, Diva do Couto G.. Meninas e Meninos na Escola: a modelagem das diferenças. In: SWAIN, Tânia Navarro (org.). Feminismos: Teorias e Perspectivas. Textos de História: Revista do Programa de Pós-Graduação em História da UNB, Brasília, UNB, vol. 8, n.1/2. 2000.

${ }^{8}$ A categoria de gênero surge no na década de 1970 durante as agitações feministas, pesquisadoras estadunidenses buscaram "desnaturalizar" as concepções acerca do feminino e do masculino bem como avaliar a relação entre ambos. Essas pesquisadoras "queriam evidenciar o caráter fundamentalmente social das distinções baseadas no sexo" (SCOTT, 1990, p.72).
} 
A atual historiografia problematizou a tradicional visão "essencialista” sobre o feminino, alimentada principalmente pela igreja católica. A mulher ideal, universal, cede lugar às mulheres, diversas, ativas, plurais, inseridas em contextos distintos, mulheres que não apenas se submetiam aos efeitos da história, mas que também foram analisadas como sujeitos históricos.

As mulheres reivindicam a construção de uma nova linguagem, que revele a marca específica do olhar e da experiência cultural e historicamente constituída de si mesmas. Mais do que a inclusão das mulheres no discurso histórico, trata-se, então, de encontrar as categorias adequadas para conhecer os mundos femininos, para falar das práticas das mulheres no passado e no presente e para propor novas possíveis interpretações inimagináveis na ótica masculina (RAGO, 1998, p.95).

No início do século XIX, no Brasil, já existiam mulheres que se dedicavam a escrever poemas sobre assuntos considerados não muito femininos, como política9. No mesmo século mulheres que assinavam pseudônimos masculinos ganhavam fama publicando em jornais. A imprensa ${ }^{10}$ constituiu um importante instrumento para divulgação das ideias femininas desde a revolução francesa em $1789^{11}$, mas no mundo o primeiro periódico feminino foi o Lady's Mercury

\footnotetext{
9 Maria Clemência da Silveira Sampaio (1789-1862), nascida no Rio Grande do sul, ficou conhecida entre os poetas da independência, após escrever o livro Versos Heroicos, para homenagear o recém-coroado Imperador D. Pedro I.

10 Tânia de Luca (2008) defende que a imprensa se tornou uma preciosa fonte para os estudos sobre a história das mulheres. Através dos jornais revistas os estudos de gênero puderam analisar as representações femininas, as práticas de consumo e os ideais de felicidade, feminilidades e masculinidades ${ }^{10}$.
}

que surgiu em 1693 na Inglaterra e servia como um tipo de "consultório sentimental" (BUITONI, 1981).

O primeiro jornal escrito por elas e para elas, a circular em terras brasileiras foi o Jornal das senhoras em $1852^{12}$, que tinha o objetivo "propagar a ilustração, e cooperar com todas as suas forças para o melhoramento social e para a emancipação moral da mulher" ${ }^{13}$. Seguindo a mesma proposta dos jornais femininos dos grandes centros, no estado de Goiás no início do século XX, circularam na antiga capital do estado dois periódicos femininos.

O primeiro foi $A$ Rosa (1917) e o segundo foi O lar (1932). Este último que circulou na cidade de Goiás entre os anos de 1926 até 1932, tinha como diretora Oscarlina Alves Pinto. O Lar, periódico literário e noticioso, contou com um o corpo editorial composto majoritariamente por mulheres. A proposta desses jornais, segundo suas próprias idealizadoras, era promover o progresso moral feminino resguardando direitos femininos domésticos, como a maternidade, garantir a harmonia e o bom funcionamento da família, mas também reivindicou novos direitos como o direito de voto que foi uma das bandeiras do jornal.

O Lar era o espelho da alma das mulheres goianas burguesas, pois eram elas que

\footnotetext{
11 Excluídas da Declaração dos direitos do homem e do cidadão, mulheres como Olympe de Gouges (1748-1793), passam a distribuir panfletos reivindicando a participação feminina da política.

12 Já em meados do XIX já haviam jornais destinado ao público feminino, mas eram escritos por homens, como o caso do Espelho Diamantino (1827), primeiro jornal voltado para público feminino no Rio de Janeiro.

13 (NORONHA, 1852, $\mathrm{n}^{\circ} 1, \mathrm{p} .1$ ).
} 
frequentavam as escolas e aprendiam a ler e a escrever. O Lar representa unicamente essas mulheres, as quais reportavam ao feminismo trazendo referências nacionais de Berta Lutz e o consideravam um movimento importante, que estava acontecendo em diferentes regiões do país e também em Goiás (DE PAULA, 2014, p.51).

Parte desses jornais especializados na "outra metade do gênero humano", escritos especificamente por mulheres que se multiplicavam a partir do final do século XIX, teve por objetivo divulgar e valorizar as produções literárias femininas se tornando assim um dos principais espaços para publicação dos poemas, contos e crônicas escritas por elas mãos femininas.

A luta pelo reconhecimento intelectual e artístico, também foi um longo e árduo caminho trilhado pelas escritoras, tendo em vista a alfabetização feminina foi tardia e a escrita consolidou-se como uma atividade essencialmente masculina.

$\mathrm{Na}$ História da Humanidade, a Literatura foi e perdura como uma das aventuras próprias do espírito, como ela é também uma experiência intelectual e uma atividade transcendental. No entanto, a Literatura também foi uma ocupação, especialidade e profissão destinada exclusivamente aos homens. Essa Literatura fez-se masculina e hegemônica (TAYASSU, 2015, p.207).

A historiografia e os estudos literários se mantiveram fieis e atentos às produções de autoria

\footnotetext{
${ }^{14}$ A Academia Brasileira de Letras criada em 1897, mas não permitiu a participação feminina até 1976. Antes disso, ainda em 1930, Amélia de Freitas Beviláqua (1860- 1946), escritora, jornalista, ativista nos direitos das mulheres no Brasil, entrou com o pedido formal para participar, mas teve seu pedido negado pela Academia.
}

masculina do que feminina, como consequência disso está o fato de que dentre as maiores figuras da literatura mundial, poucas são mulheres. Inúmeras escritoras, com imenso valor literário, competência e criatividade, ficaram de fora das importantes instituições como as Academias de Letras $^{14}$ ou premiações como o Nobel de literatura ${ }^{15}$.

Nessa ótica, defendemos que o exercício da escrita e da prática literárias entre as mulheres foi, e ainda é por si só, uma prática de resistência, principalmente, quando analisamos todos os obstáculos que o "sexo frágil" teve que transpor para ser reconhecido, para ter o direito de estudar e se expressar através da leitura, dificuldades que ainda hoje, nem sequer foram totalmente superadas.

As mulheres que ousavam publicar seus textos tinham que enfrentar preconceitos e insultos, como relatou a escritora goiana Cora Coralina, que também teve textos publicados em periódicos goianos no século XX:

\begin{abstract}
Meninas, não aceitavam delas senão a linguagem corriqueira e vulgar da casa. Palavrinha diferente, apanhada no almanaque ou trazida de fora, logo a pecha de sabichona, dona gramática, pernóstica, exibida. Um dia fui massacrada por ter falado lilás em vez de roxo claro. [...] A gente era vigiada, tinha uns preconceitos arrogantes de ridicularizar e limitar jovens personalidades. (CORALINA, 1983, p. 44 APUD CURADO, 2003, p.23).
\end{abstract}

15 “O prêmio é destinado a qualquer escritor de nacionalidades diversas. Quem escolhe os candidatos ao prêmio é a Academia Sueca, e os nomes dos escritores são anunciados no começo do mês de outubro de cada ano. Ao total 112 escritoras/escritores já receberam o prêmio, sendo apenas 14 mulheres" (SOUZA, 2016, p. 47). 
Os obstáculos não foram vencidos apenas com a alfabetização. Além disso, a produção feminina era tratada com condescendência ou hostilidade. A crítica literária era mais dura perante textos de autoras, uma estratégia para desestimular, desencorajar a prática da escrita literária feminina. "As críticas realizadas em torno da escrita produzida por mulheres eram extremamente cruéis, no qual era afirmado categoricamente que o universo da escrita não era o lugar apropriado para elas" (SOUZA, 2016, p.57). O que acabou fazendo com que muitas autoras, temerosas da exposição, recorressem aos pseudônimos. Uma forma encontrada por elas, para não ter que abandonar a caneta, mantendo a integridade, diante a ferocidade das críticas.

Estimular e enaltecer as mulheres escritoras estavam dentro da proposta desses jornais de garantir a emancipação intelectual e o progresso moral feminino, embora as aspirações dessas mulheres ainda estivessem estritamente ligadas ao lar. A imprensa em grande medida reforçava os papeis femininos de mãe e rainha do lar, na medida em que se concentrava em instruir e conscientizar as mulheres sobre suas funções na sociedade. Segundo Sávia Barros Diniz (2013) a imprensa reafirmou-se como instrumento de constituição e validação de modelos de comportamento. Entretanto devemos considerar que esses comportamentos ao longo do século XX foram se transformando.

O desenvolvimento tecnológico através de novas mídias e meios de comunicação, a disputa entre socialismo e capitalismo, as discussões relacionadas à cultura na pós-modernidade, as duas grandes guerras mundiais, dentre outros acontecimentos, marcaram a experiência de vida dos indivíduos no século XX. Esses eventos refletiram profundamente nas relações entre homens e mulheres, principalmente com a inserção cada vez maior das mulheres no mercado de trabalho, a articulação do movimento feminista e a revolução sexual, engendrada pelo surgimento dos métodos contraceptivos. No Brasil, durante o século XX, temos o desenrolar de uma república cujo percurso foi marcado, ora por retração, ora por ampliação, de direitos e conquistas sociais, como a garantia do voto feminino e dos direitos trabalhistas com Getúlio Vargas e a onda conservadora da ditadura militar de 1964.

"Desde o início do século XX, a sociedade brasileira esperava que as mulheres desempenhassem novos papeis no âmbito doméstico e na esfera pública” (AREND, 2013, p.72), dessa forma, as identidades femininas hegemônicas e comuns até o século XX, orientadas pela doutrina cristã e que enaltecia as mulheres como mães e esposas, passaram a dividir espaço com uma identidade feminina mais ousada e modernas que axaltavam a mulher escritora, cientista, médica, advogada, eleitora. Diante as mudanças às mulheres se organizaram para pensar a realidade social, principalmente através da imprensa. Esses jornais eram importantes veículos de disseminação de ideias femininas a respeito da própria existência, uma existência sensível às mudanças políticas e culturais que marcaram o Brasil e o mundo durante o século XX.

\section{O FEMININO E O EXISTENCIALISMO: ALGUMAS CONSIDERAÇÕES FINAIS.}


A filósofa Simone de Beauvoir (19081986), em sua obra O Segundo Sexo, demonstra que nem a biologia, nem a psicanálise nem o materialismo são suficientes para definir a mulher. “O existencialismo de Beauvoir não aceita uma visão essencialista do sujeito, pois compreende os indivíduos como construções históricas" (MENEZES, 2001, p.3), isso é evidenciado pela mais famosa frase da filósofa: Não se nasce mulher, torna-se. Nesse sentido não é possível pensarmos identidade, não de maneira fixa ou enquanto esse conceito estiver relacionado a uma essência.

O que define o ser humano é aquilo que ele livremente escolheu ser, tomando por base apenas o seu pensamento e as ações que praticou, independente de sua condição social ou econômica, de lei moral ou de lutas de classe. A essência humana formavase nesse processo mutável e não a partir de princípios absolutos (PASSOS, 2000, p.42).

Tomando como base a máxima do existencialismo de que a existência precede a essencial, percebemos que a essência não é totalmente refutada, há, na verdade, uma proposta de que se ela existe, não é de maneira inata ou $a$ priori, e sim construída, a posteriore, dependendo intimamente das experiências do indivíduo que se constrói historicamente.

A mulher é o outro do homem, apenas o masculino, ao longo dos séculos, foi capaz de se autodefinir, enquanto sobre o feminino pesam a biologia e a imanência, restando-lhe apenas alteridade para se constituir enquanto fêmea. "Para Beauvoir, o que justifica a existência humana é o movimento incessante que o ser humano faz de transcendência em relação a si mesmo, mas o homem especificamente negou esse movimento de transcendência em relação às mulheres" (MENEZES, 2001, p.12).

A condição feminina diante a opressão é delicada e complexa, mas para a filósofa, a mulher não é necessariamente vítima, na medida em que, mesmo oprimida ela tem escolhas, ela possui certa liberdade, - que é um dos princípios básicos do existencialismo -, para seguir, ou não, os comportamentos estabelecidos socialmente como femininos. A mulher, portanto, está "condenada" a fazer escolhas para organizar sua existência, mas ela também deve assumir as consequências com consciência e responsabilidade sem agir de má fé.

A imprensa feminina, principalmente a imprensa anarquista e feminista, incentivaram as mulheres a desbravarem caminhos alternativos para existência feminina. A mineira Maria Lacerda de Moura (1887-1945) foi uma dessas mulheres extraordinárias no sentido de mulher fora do comum. Da mesma forma Beauvoir, ela não foi uma mulher convencional, extrapolou a conduta estabelecida para o e gênero feminino em sua época, instigando e propondo para as mulheres novas maneiras de viver. Divorciada, Maria Lacerda de Moura escrevia para jornais anarquistas como $A$ Plebe e $O$ Combate, denunciando a violência e a exploração capitalista sobre as mulheres e repensando a moral sexual feminina ao criticar a virgindade e defender o amor livre.

O feminismo foi um dos movimentos intelectuais que propiciou a reflexão sobre a condição feminina e auxiliou as mulheres nessa busca por superar ou amenizar a violência e a 
submissão e moldar uma identidade feminina específica. O feminismo pode ser pensado como uma ação política e filosófica transformadora que encontrou respaldo na imprensa, conquistando admiradores e inimigos.

Entre as questões sociais, uma das quais tem agitado o espírito moderno, desde a aurora indecisa do armistício de 1918, é a avalanche das novas correntes feministas que, na América como na Ásia e, principalmente, na Europa, empolga a atenção dos graves homens votados aos estudos dos fenômenos sociopolíticos $[\ldots]^{16}$.

Reflexo do movimento feminista no Brasil, em Agosto de 1922 foi fundada Federação Brasileira pelo progresso feminino (FBPF), por Bertha Lutz no Rio de Janeiro, esse grupo inspirou a fundação de grupos semelhantes por todo Brasil, inclusive em Goiás $^{17}$, que tinham como alguns objetivos garantir educação feminina, incentivar a união entre as mulheres, reivindicar direitos, orientar as mulheres sobre a profissão e a maternidade.

Só os avessos as modernismo movimento da remodelação política contemporânea, é que embaciam com má vontade e injurias apoplécticas de crianças grandes e mal educadas o objetivo grandioso das verdadeiras feministas que veem no sufrágio não um meio de se elevarem, de apareceram, mas o campo de ação onde elas pretendem corroborar, em contato intimo com os homens, o ideal comum de todos os povos: o

\footnotetext{
16 Leo Lynce. O Lar, 30 de Outubro de 1926.

17 Em Goiás é fundada em 1931 por Consuelo Caiado a Federação Goyana pelo Progresso Feminino.
}

engrandecimento, a fortaleza, a gloria de sua Pátria ${ }^{18}$.

Ao longo do século XX, as mudanças políticas e sociais, os ideais de progresso e modernização, bem como correntes filosóficas como o existencialismo de Simone Beauvoir favoreceram para que a essência feminina fosse contestada. As mulheres, apesar de toda vigilância, controle e submissão, sempre tiveram que decidir pelas suas vidas, e nesse século em questão os dilemas giravam entorno da opção ou não pela maternidade, reivindicar ou não uma vida sexual ativa, seguir uma carreira profissional estável, casar ou se dividir em múltiplos deveres, viver de maneira autônoma ou escolher a tutela masculina. Ainda que massacradas pelo peso das imposições sociais, surgiram, paulatinamente, ao longo do século XX, inúmeras narrativas que sugeriram novas possibilidades para existência feminina. Esses dilemas entre identidades múltiplas e escolhas possíveis se propagaram pela imprensa feminina durante o século $\mathrm{XX}$, e foram identificados e problematizados pelos historiadores, que movidos por problemas contemporâneos, se dedicaram a entender e a narrar trajetórias discursivas que edificaram sujeitos históricos marcados pelas diferenças de gênero.

\section{BIBLIOGRAFIA}

BEAUVOIR, Simone de. O segundo sexo. Vol. 1 Fatos e mitos e Vol. 2. Experiência de vida.

${ }^{18}$ Grace Machado. O Lar, 15 de janeiro de 1928. 
Trad. Sérgio Milliet. Rio de Janeiro: Nova Fronteira; 1980.

BUITONI, Dulcilia. Mulher de papel: representações de mulheres pela imprensa feminina brasileira. São Paulo: Loyola; 1981.

DOMINGUES, Ivan. A experiência do tempo e da história. In: O fio e a trama: Reflexões sobre o tempo e a história. Belo Horizonte: Editora UFMG; 1996.

DINIZ, Sávia Barros. Mulheres na imprensa: Representações femininas no Correio Oficial, Cidade de Goiás (1930-1936). [Dissertação] Goiânia: Universidade Federal de Goiás; 2013.

DE LUCA, Tania Regina. Fontes impressas, história dos, nos e por meio dos periódicos. In: PINSKY, Carla Bassanezi (Orgs). Fontes Históricas. 2.ed., São Paulo: Contexto; 2008.

HALL, Stuart. Quem precisa de identidade? In: SILVA, Tomas Tadeu (Org.). Identidade e diferença: a perspectiva dos estudos culturais. Petrópolis: Vozes; 2000.

LAGO, Mara Coelho de Souza. Identidade: a fragmentação do conceito. In: SILVA, Alcione leite da; LAGO, Mara Coelho de Souza; RAMOS, Tânia Regina Oliveira (Orgs). Falas de Gênero: Teorias, Análises e Leituras. Florianópolis: Editora Mulheres; 1999.

MENEZES, Magali Mendes. A mulher enquanto o outro na obra de Simone Beauvoir. Diálogos, Canoas. 2001; nº 2: 89-109.

ORTEGA Y GASSET, José. A História como sistema. In: Histórica como sistema. Mirabeua ou o político. Trad. Juan A. Gili Sobrinho e Elizabeth Hanna Cortes Costas. Brasilia: Editora da Universidade de Brasília; 1982.

PASSOS, Elizete. O existencialismo e a condição feminina. In: MOTTA, Alda Brito; SARDENBERG, Cecilia; GOMES, Márcia (Orgs). Um diálogo com Simone de
Beauvoir e outras falas. Salvador: NEIM/UFBA, Coleção Bahianas; 2000.

PEDRO, Joana Maria Pedro (Org.). Nova história das mulheres no Brasil. São Paulo: Contexto; 2012.

PERROT, Michelle. Minha história das mulheres. Trad. Angela M. S. $2^{\circ}$. Ed. São Paulo: Contexto;2015.

RAGO, Margareth. Descobrindo historicamente o gênero. In: Cadernos Pagu. trajetórias do gênero, masculinidades. Núcleo de Estudos de Gênero/UNICAMP. $1998 ; n^{\circ} .11$.

RICOUER, Paul. Tempo e narrativa: A tríplice mimese. In: Tempo e narrativa. Tomo I. Campinas, SP: Papirus; 1994.

RUSEN, Jorn. Pragmática - A constituição do pensamento histórico na vida prática. In: Razão Histórica. Brasília: Editora da UNB; 2008.

SARTRE, Jean-Paul. O existencialismo é um humanismo; A imaginação; A questão de método. Trad. Rita Correia Guedes, 3.ed. São Paulo: Nova Cultural (Coleção Os Pensadores); 1987.

SCOTT, Joan Wallach. Gênero: uma categoria útil de análise histórica. Educação \& Realidade. 1995; vol. 20, nº 2, jul./dez.

SCOTT, Joan Wallach. Experiência. In: SILVA, Alcione leite da; LAGO, Mara Coelho de Souza; RAMOS, Tânia Regina Oliveira (Orgs). Falas de Gênero: Teorias, Análises e Leituras. Florianópolis: Editora Mulheres; 1999.

SOIHET, Raquel. História das Mulheres. In: CARDOSO, Ciro Flamarion; VAINFAS, Ronaldo (Orgs.). Domínios da História: ensaios de teoria e metodologia. Rio de Janeiro: Campus; 1997.

SOUZA, Talita Micheli de. História de mulheres escritoras em Goiás: atravessando trajetórias e produções literárias. [Dissertação] de mestrado. 
Goiânia: Universidade Federal de Goiás; 2017. 